\title{
O método clínico revisitado: uma proposta interdisciplinar
}

Sally Karina Brodski*, Claudio Simon Hutz**, Cassiano Kuchenbecker Rösing***, Solange Maria Beys***, Clarissa Marceli Trentini****

\author{
* Estudante de Pós-Graduação (Mestrado), Instituto de Psicologia, \\ Universidade Federal do Rio Grande do Sul \\ ** Professor Titular, Instituto de Psicologia, Universidade Federal do \\ Rio Grande do Sul \\ *** Professor Associado, Faculdade de Odontologia, Universidade \\ Federal do Rio Grande do Sul \\ **** Professor Adjunto, Instituto de Psicologia, Universidade Federal do \\ Rio Grande do Sul
}

\section{RESUMO}

Este trabalho teve como objetivo descrever uma nova visão político-pedagógica transdisciplinar enfocando o método clinico em odontologia através do olhar da Psicologia. Tornou-se possível através da implantação da mudança curricular praticada na Faculdade de Odontologia da Universidade Federal do Rio Grande do Sul a partir de 2005.

\section{DESCRITORES}

Psicologia em saúde. Educação. Odontologia.

E tudos que abordem a relação do profissional/ irurgião-dentista com seu paciente não estão ainda muito desenvolvidos, havendo poucas publicações. ${ }^{9}$ Nesse sentido, permanece o questionamento: por que, às vezes, o profissional que é considerado apto tecnicamente não consegue obter êxito no atendimento de um paciente que, por sua vez, parece estar motivado a se tratar. As dúvidas abaixo citadas são freqüentes no processo de aprendizagem em saúde:

- Por que o paciente nem sempre colabora para o bom desempenho do trabalho do profissional?

- Por que às vezes aquele profissional sabe tudo na teoria, mas na prática não funciona?

Estas e outras tantas perguntas trazem ansiedade aos alunos de odontologia ao se depararem pela primeira vez com um paciente aos seus cuidados na clinica odontológica. No entanto, sabe-se que enquanto houver perguntas haverá espaço ao aprendizado.

Este é o papel que o psicólogo pretende ocupar ao transmitir alguns conhecimentos de psicologia, ensinando a respeito do desenvolvimento humano e do vínculo, ao trabalhar de forma interdisciplinar com os alunos da Faculdade de Odontologia da Universidade Federal do Rio Grande do Sul. Segundo Caon $(1998)^{2}$ quando um pesquisador tem um problema não solucionado em sua área temática, a transdisciplinaridade deve ser evocada para provocar um diálogo com as outras áreas.

Para Meireles (1999) ${ }^{4}$ a interdisciplinaridade é considerada uma inter-relação e interação das disciplinas a fim de atingir um objetivo comum. Estabelecese uma interdependência entre as disciplinas, busca-se o diálogo com outras formas de conhecimento e com outras metodologias, com o objetivo de construir um novo conhecimento. Dessa maneira, a interdisciplinaridade se apresenta como resposta à diversidade, à complexidade e à dinâmica do mundo atual.

Já para Vilela e Mendes (2003), ${ }^{11}$ o ensino baseado na interdisciplinaridade tem grande poder estruturador. Nesse sentido, os conceitos e procedimentos encontram-se organizados em torno de unidades mais globais, em que várias disciplinas se articulam.

O objetivo deste diálogo seria promover trocas e aproximações para que o problema possa ser compartilhado e novas soluções sejam geradas. Este seria o verdadeiro sentido da produção tecnológica num domínio de diversidades representando um grupo composto por mais de uma área de conhecimento.

O psicólogo por sua vez, por estudar em profundidade o desenvolvimento humano e o papel dos vínculos na formação das relações, tem a oportunidade de trazer estes construtos para dentro da área da odontologia. Como as relações humanas são interativas e di- 
nâmicas, nem tudo o que ocorre pode ser visto. Muito do que se dá na interação entre paciente e cirurgiãodentista está no campo da percepção e das emoções. E é com este tipo de material que o psicólogo está treinado para trabalhar e, portanto, assessorar e assim estimular esta sensibilidade e desenvolver a habilidade de tomar contato com seus sentimentos no aluno.

Segundo Seger (1988) $)^{9}$ quando estamos "ligados" ou vinculados, somos co-responsáveis pelo que acontece na relação com nosso paciente. Portanto, encorajar os alunos a falar de suas percepções, sentimentos na relação profissional-paciente, significa atribuir ao estudante a sua parcela de responsabilidade pelo sucesso ou fracasso do atendimento, do ponto de vista relacional.

O vínculo diz respeito a uma estrutura complexa que incluiu duas pessoas e sua representação mútua, melhor dizendo, como uma percebe a outra ${ }^{5}$ através dos processos de comunicação e aprendizagem. Ainda neste sentido, sabe-se que todo o vínculo compreendido desta maneira, pressupõe um emissor, um receptor, uma codificação e uma decodificação da mensagem.

Portanto, o vínculo visto assim é sempre bicorporal, onde dois atores estão em cena, e também tripessoal, devido a presença internalizada positiva ou negativa que nos acompanha nas relações que desenvolveremos no decorrer de nossas vidas. Estas ligações que estabelecemos através dos nossos primeiros vínculos, inicialmente concretas, remetem às mães com as quais éramos atados através do cordão umbilical.

Posteriormente, o cordão afetivo, portanto, subjetivo e invisível, é aquele através do qual nos desenvolvemos emocionalmente. $\mathrm{O}$ bebê então depende tanto dos cuidados físicos básicos, como a nutrição, higiene e outros, quanto das relações afetivas para passarmos do estado de "maternados" para posteriormente podermos "maternar". ${ }^{9}$ Precisamos ser cuidados para depois sabermos e podermos cuidar. Assim, através da relação de dependência que se estabelece, ou seja, quando a necessidade que temos e que somente será satisfeita por um outro, é que o vínculo se estabelece.

Portanto, promovendo o estudo e o debate sobre o vínculo, sobre o desenvolvimento humano e de noções fundamentais acerca da psicopatologia, o Psicólogo estará auxiliando o aluno a receber o paciente. Desta forma, também estará se promovendo um espaço para que esta experiência seja bem sucedida.

Schimith e Lima $(2004)^{8}$ acreditam que o acolhimento e vínculo dependem do modo de produção do trabalho em saúde. O acolhimento possibilita regular o acesso através da oferta de ações e serviços mais adequados, contribuindo para a satisfação do usuário. O vínculo entre profissional e paciente estimula a autonomia e a cidadania, promovendo sua participação durante o recebimento do atendimento.

O objetivo do presente trabalho é fazer um relato de experiência vivenciada na Faculdade de Odontologia da Universidade Federal do Rio Grande do Sul, salientando a abordagem interdisciplinar, com ênfase no ensino de Psicologia na Clínica Odontológica uma re-significação do método clínico.

\section{RELATO DE EXPERIÊNCIA}

A Faculdade de Odontologia da Universidade Federal do Rio Grande do Sul, no início dos anos 2000, frente a uma consciência coletiva de que o modelo curricular adotado desde os anos 1980 estava ultrapassado, aliado ao processo nacional de implementação das Diretrizes Curriculares Nacionais, decidiu fazer uma profunda alteração no seu currículo.

Para tanto, decidiu que um amplo processo de discussão seria realizado com a comunidade acadêmica - docentes, técnicos e estudantes - procurando construir coletivamente um currículo que atendesse às necessidades da comunidade e do sistema de saúde vigente. Uma avaliação realizada em $2000,{ }^{6}$ demonstrou que os estudantes da Universidade, a despeito de um nível interessante de satisfação com o currículo, apresentavam alguns pontos críticos a serem abordados, o que incluía dificuldades no atendimento clínico, especialmente na falta de integração entre especialidades odontológicas, assim como com outras áreas do conhecimento em saúde. Nessa mesma avaliação, na publicação que focou sobre o ensino de ciências básicas, ${ }^{7}$ a maioria dos estudantes sugeriu que a formação básica do dentista deveria ser a mesma de um médico. Nessa avaliação, fundamentalmente disciplinas das ciências biológicas eram vislumbradas, com um importante esquecimento das ciências humanas e sociais.

Durante as discussões sobre o novo modelo curricular, metodologias ativas de discussão foram adotadas, com oficinas de trabalho, presença de convidados de outras unidades da Universidade, assim como de outras Universidades para relatarem suas experiências e motivarem as discussões.

O processo de discussão comunitária durou mais de 3 anos, com reuniões semanais em grupos menores e mensais com toda a comunidade, o que gerou o presente projeto político-pedagógico da Faculdade de Odontologia da UFRGS. ${ }^{10} \mathrm{O}$ perfil do profissional aprovado foi ao encontro daquele sugerido nas Dire- 
trizes Curriculares, com uma sólida formação técnicocientífica e humanista.

A partir da ênfase na questão humanista, a Faculdade decidiu pela adoção dos conceitos humanísticos na formação de seus alunos, trazendo para o seu currículo o olhar epistêmico das ciências humanas e sociais. Tentando fugir da organização disciplinar clássica, entretanto atendendo a necessidades organizacionais da Universidade, foi adotado o desenho de disciplinas departamentais e inter-departamentais, essas últimas integrando vários departamentos da Universidade, independentemente de unidade de origem.

A experiência a ser relatada nesse artigo envolve o ensino de Psicologia no curso de Odontologia. As demais áreas do conhecimento podem ser reconhecidas e entendidas a partir do projeto político pedagógico do curso de Odontologia. ${ }^{10}$

Assim, a inserção da Psicologia no currículo da Faculdade de Odontologia da UFRGS como disciplina formal se dá em 3 momentos:

1. No segundo semestre, através da disciplina de Psicologia Geral, com 30 horas;

2. quinto semestre, através da disciplina de Psicologia Clínica, com 30 horas;

3. sétimo semestre, através da disciplina de Introdução ao Manejo da Criança e do Adolescente, com 15 horas.

A lógica da participação da Psicologia no ensino de Odontologia, com a simples apresentação do exposto acima fica totalmente descontextualizada. Deste modo, serão descritos alguns aspectos dessa participação.

O início da formação do profissional envolvendo a psicologia já acontece no segundo semestre. Nesse momento, o aluno já experienciou no início do curso disciplinas que envolvem o ser humano e seus contextos na formação (Introdução à Odontologia, Saúde e Sociedade, Ética e Bioética, Introdução às Ciências Sociais para Odontologia, todas essas integradas por um Seminário de Integração II). Desta forma, os conteúdos de psicologia, são introduzidos sob uma base epistêmica dentro das ciências humanas. Ademais, o primeiro contato teórico com a psicologia coincide com a primeira vivência dos alunos no método clinico no segundo semestre da faculdade, realizada no Acompanhamento Clínico I.

A segunda inserção da Psicologia - a mais significativa do curso - se dá na quinta etapa, quando o aluno é exposto à disciplina de Psicologia Clínica, concomitantemente à Disciplina de Clínica Odontológica I. Esse é o momento mais importante da formação envolvendo a Psicologia, pois é aí que o aluno inicia suas atividades com pacientes, identificando-se como profissional. A construção da identidade do cuidador se materializa nesse semestre. O interessante é que o professor de Psicologia, assim como alunos de pós-graduação de psicologia realizando seu estágio docente, atua na Clínica Odontológica I. Assim, as discussões feitas na disciplina de Psicologia Clínica são vinculadas aos pacientes da Clínica Odontológica. Ademais, nas discussões de casos clínicos na Odontologia, o professor da área de psicologia tem ativa participação quando solicitado.

Constrói-se assim um olhar interdisciplinar no método clínico de intervenção em Odontologia que funda o paciente como um todo, indo além da simples intervenção bucal. Portanto, transitando para a corporeidade. ${ }^{1}$ As experiências vivenciadas na clínica odontológica geraram visitas domiciliares espontâneas, contatos com as famílias dos pacientes, interações além da atividade clínica clássica. Desta forma, a humanização do atendimento odontológico tem sido ampliada.

Além disso, no sétimo semestre, antes do início das atividades de Clínica Infanto-Juvenil, aspectos psicológicos de crianças e adolescentes são abordados.

A partir dessa inserção, muitos frutos têm sido colhidos, especialmente porque as barreiras entre o dentista e o psicólogo ficam rompidas, fazendo com que os alunos de outras fases (posteriores) continuem a desfrutar da consultoria em Psicologia. Isso inclusive gerou experiências muito importantes da solicitação da presença da consultoria em Psicologia para todas as atividades clínicas. Assim, hoje, em um turno da semana, no curso de Odontologia da UFRGS, há a presença do psicólogo na clínica, para atender às necessidades dos pacientes em atendimento. Também, alunos com necessidades de atendimento são orientados, o que efetivamente permite que a interdisciplinaridade esteja em prática.

No momento, projetos de pesquisa conjuntos têm sido iniciados, assim como uma perspectiva de extensão está em geração, o que coloca todos os aspectos fundamentais da universidade conjuntamente trabalhados.

\section{DISCUSSÃo E CONSIDERAÇÕES FINAIS}

Desta experiência ficou que os alunos em debate consensual em conjunto ao professor concluíram que é necessário que estes se apropriem de conceitos de psicopatologia. Cabe ressaltar que os estudantes de odontologia também são atores de seu processo de aprendizagem, pois este nunca termina. Com isto se pretende fortalecer a prática clinica do cirurgiãodentista ainda que não se os habilite a atender as de- 
mandas emocionais, e sim que saibam quando devem e podem intervir e quando não devem fazê-lo. ${ }^{3}$

Os alunos compreendem que podem indicar ou solicitar um profissional de psicologia quando julgarem necessário para seus pacientes. Esta é uma prática estimulada que fará parte de sua formação profissional diferenciando-o. Assim, se necessário for, poderão encaminhar o paciente para o profissional adequado para mais adiante ou paralelamente, prosseguir com o tratamento odontológico.

Portanto, o enfoque interdisciplinar nos ensina que o olhar engrandece a integralidade, contrariamente ao senso comum que a complementaridade retira a identidade do profissional. Pode-se estabelecer uma analogia entre o temor do olhar interdisciplinar versus destruição de identidade específica, assim como o temor entre a relação do vínculo e o temor ao apego. Esta situação é verificada com freqüência no senso comum frente a situações novas, principalmente quando se trata de mudanças curriculares.

Em consonância com Seger $(1998)^{9}$ observou-se que a vinculação que se estabelece no atendimento, não impossibilita os sujeitos de se separarem, não escraviza o profissional ou paciente; pelo contrário, liberta-os, na medida em que os torna mutuamente responsáveis por permanecerem ou não em relação. Isto fortalece o pacto necessário no método clinico entre paciente e profissional no sentido de estabelecer responsabilidades mútuas para o sucesso da terapia odontológica. Principalmente no que se refere à mudança de comportamentos, onde pacientes e profissionais interagem de forma ativa, na construção da resposta clínica.

Já o apego implica na dependência do paciente em relação ao profissional, contrariando a própria definição de método ampliado de cura. Isto significa que curar o paciente sempre implica em aumentar a autonomia do mesmo sobre o seu corpo ${ }^{1}$ e, portanto, desenvolvendo a capacidade prevenção e responsabilização pelos seus próprios cuidados. Nesse sentido, apropriar-se de si mesmo, possibilita que o sujeito exerça a cidadania dentro do conceito ampliado.

Este tipo de vivência, portanto, concretiza o conceito de integralidade da atenção que é um dos conceitos fundantes da reforma sanitária brasileira. Este faz parte, portanto, do Sistema Único de Saúde (SUS).

A experiência ora relatada tem sido frutífera e carece de avaliação ao longo do tempo, assim como de ampliação. Entretanto é o início de um fazer em saúde, desvinculado das barreiras entre diferentes olhares das ciências da saúde.

\section{ABSTRACT}

The clinical method revisited: an interdisciplinary proposal

The purpose of this paper was to describe a new political-educational transdisciplinary perspective, focusing on the dental clinical method as viewed by Psychology. This new perspective was formed after the new dental curriculum was implemented in the School of Dentistry at the Federal University of Rio Grande do Sul (UFRGS) in 2005.

\section{DESCRIPTORS}

Behavioral medicine. Education. Dentistry.

\section{REFERÊNCIAS}

1. Assmann H. Sete colocações sobre corporeidade e movimento, Anais do 3 Congresso Latino Americano da ICHPER-SD - Foz do Iguaçu, 1996.

2. Caon JL. Da existência analfabética à existência analfabetizada. Revista do GEEMPA, 1998 6:120-127.

3. Klatchoian DA. Psicologia Odontopediátrica. São Paulo: Servier, 1993.

4. Meireles BH, Erdmann AL. A questão das disciplinas e da interdisciplinaridade como processo educativo na área da saúde. Texto Contexto Enfermagem 1999; 8(1):149-65.

5. Pichon-Rivière E. Teoria do Vínculo. São Paulo: Martins Fontes, 1995.

6. Rösing CK, Silva DT, Deon P, Oppermann RV, Gjermo P. Evaluation of 4 dental curricula based on students' expectations and satisfaction - report of Brazilian and Norwegian experiences. Revista da ABENO, 2008 (accepted).

7. Rösing CK, Oppermann RV, Silva DT, Deon P, Gjermo P. Students' appraisal of their dental education related to basic sciences learning: a comparison of four curricula in Norway and Brazil. Revista Odonto Ciência 2008;23(3): 234-237.

8. Schimith MD, Lima MADS. Acolhimento e vínculo em uma equipe do Programa Saúde da Família. Cad. Saúde Pública 2004; $20(6): 1487-94$.

9. Seger L. Psicologia e odontologia: uma abordagem integrada. São Paulo: Livraria Santos Editora Com. Imp. Ltda. 1998.

10. UFRGS. Projeto Político-pedagógico da Faculdade de Odontologia da Ufrgs. Universidade Federal do Rio Grande do Sul, 2004. Disponível em: http://www.ufrgs.br/odonto/projeto_ politico.pdf

11. Vilela EM. Mendes IJM. Interdisciplinaridade e saúde: estudo bibliográfico. Rev. Latino-Am. Enfermagem 2003;11(4):52531.

Recebido em 09/03/2010

Aceito em 15/06/2010 